\title{
Pituitary Agent
}

National Cancer Institute

\section{Source}

National Cancer Institute. Pituitary Agent. NCI Thesaurus. Code C2348.

Recombinant forms of the naturally occurring hormones synthesized by the pituitary gland. 